\title{
LOUIS FIGUIER EN BRASIL: ALGUNAS CONSIDERACIONES ACERCA DE LOS VULGARIZADORES DE LAS CIENCIAS EN EL ÚLTIMO CUARTO DEL SIGLO XIX
}

\author{
Kaori Kodama \\ Casa de Oswaldo Cruz-Fiocruz, Brazil \\ Email: kaori.flexor@gmail.com \\ ORCID iD: http://orcid.org/0000-0002-5327-2689
}

Recibido: 16 octubre 2015; Aceptado: 30 septiembre 2016.

Cómo citar este artículo/Citation: Kodama, Kaori (2017), “Louis Figuier en Brasil: algunas consideraciones acerca de los vulgarizadores de las ciencias en el último cuarto del siglo XIX”, Asclepio, 69 (1): p175. doi: http://dx.doi.org/10.3989/asclepio.2017.07

RESUMEN: Este artículo pretende abordar aspectos de la historia de la divulgación científica en Brasil en el siglo XIX, a través del analisis de la circulación de algunas traducciones para el portugués de las obras del vulgarizador de la ciencia francés, Louis Figuier. Sus obras, que fueron traducidas para diversas lenguas, recibieron ediciones en Brasil y en Portugal a partir de fines de la década de 1860. En este período, ganaba terreno un modelo de divulgación de las ciencias que se alineaba con la idea de ampliación de conocimientos científicos, con énfasis en las ciencias aplicadas para no especialistas - clase trabajadora, mujeres y jovenes.

Sin embargo, ese modelo fue marcado igualmente por limitaciones y discontinuidades que reflejan cuestiones sociales de fondo, en el pasaje al siglo XX. Este trabajo pretende, destacar el papel de los traductores y editores, entendidos como mediadores de las ciencias, que tenían en vista proyectos cuyo principal enfoque era la educación.

PALABRAS CLAVE: Historia de la Divulgación Científica; Mediación Cultural; Vulgarizadores Franceses; Traducción; Brasil; Siglo XIX.

\section{LOUIS FIGUIER TRANSLATED IN BRAZIL: SCIENCE POPULARIZERS IN THE LAST QUARTER OF 19TH CENTURY}

ABSTRACT: This article aims to address aspects of the history of the divulgation of sciences in Brazil in the nineteenth century, through the analysis of the circulation of some translations into Portuguese of the works of French popularizer of science, Louis Figuier. His works, which were translated to different languages, received editions in Brazil and Portugal since late 1860. During this period, a model of popularization of science for non-specialists - working class, women and youth - with emphasis on applied science was gaining terrain.

However, this model was also marked by limitations and discontinuities that reflect social issues in the passage to the twentieth century. This paper attempts to highlight the role of translators and editors, understood as mediators of science, whose projects of social reform was primarily focused in popular instruction.

KEY WORDS: History of Popularization of Science; Cultural Mediation; French Popularizers; Translation; Brazil; 19th Century.

Copyright: (C) 2017 CSIC. Este es un artículo de acceso abierto distribuido bajo los términos de la licencia Creative Commons Attribution (CC BY) España 3.0. 


\section{INTRODUCCIÓN}

Con la perspectiva del fin de la esclavitud y la modernización del país, una nueva generación de intelectuales, conocida como "la generación de 1870 ", surgía en el escenario cultural brasilero, defendiendo proyectos nacionales que ampliasen las ciencias y sus valores en el país, a través de la instrucción y de la vulgarización ${ }^{1}$ de los conocimientos científicos. Durante este período se puede observar la intensificación de las actividades de divulgación científica en el país, como observaron Massarani y Moreira (2010), al compararlo con períodos anteriores, cuando la divulgación de temas científicos era más difusa, presente en algunas publicaciones periódicas. Diferentes acciones, como los cursos públicos del Museo Nacional, principal y mayor institución de ciencias naturales del período imperial; las conferencias populares, como las ocurridas en el barrio de la Gloria, en Rio de Janeiro (Carula, 2009; Fonseca, 2007); publicaciones volcadas a la educación popular, además de obras de cuño literario que abordaban temáticas científicas, pasaron a circular con mayor frecuencia a partir de la década de 1870.

De hecho, dada la vivencia de un período en que se imponía el impacto de las mudanzas tecnológicas y científicas de la segunda revolución industrial, tales acciones venían al encuentro de proyectos que anhelaban el fomento de una "cultura científica" que mudase el perfil del país. Esta cuestión, sin embargo, se tornaba compleja, al tener en cuenta la propia condición de Brasil, de fines del período monárquico e inicio de la era republicana, cuando las posibilidades de transformaciones sociales se veían exiguamente restringidas por el abismo social y político mantenido por la esclavitud.

Las palabras del médico francés que se radicó en Brasil, Louis Couty, son bastante significativas para averiguar el deseo por una mayor cultura de las ciencias y sus valores. En un artículo publicado en la $R e-$ vista Brasileira ${ }^{2}$, en 1879, Couty defiende el progreso de las ciencias experimentales en el país sobre todo a través de la instalación de laboratorios y de investigaciones originales en suelo brasilero. Preconizaba además la necesidad de ampliar el círculo de interés por temáticas científicas en la arena pública. De este modo, creía que era necesario fomentar la pasión por temas científicos "de la menor, como de la mayor importancia", de modo que cualquier descubrimiento interesante pudiese tornarse "asunto de conversaciones y discusiones tanto de los sabios, como de todas las personas instruidas" (Couty apud Vergara, 2003, p.79). Así, postulaba: "La gran corriente científica que ya existe entre los sabios de Brasil, profesores, médicos, etc., debe tornarse verdaderamente general..." (Couty, 1879, p.233)

En cuanto el apelo de Couty era dirigido a los 'hombres instruidos' (con el género así definido), con el objetivo de posibilitar una mayor afluencia y estímulo de la carrera científica en el país, otros agentes que buscaban la ampliación del público no especialista para las ciencias se volcaban para la educación de diferentes grupos, incluyendo mujeres y niños. Dentro de ese grupo, es notable la presencia de traducciones de obras de libros y periódicos escritos por autores franceses, indicando una fuerte relación de los mediadores de las ciencias con la producción francesa iniciada por vulgarizadores. Un ejemplo es el periódico $A$ Mãi de Familia (1879-1888) inspirado en el periódico francés La jeune mère, y editado por el médico Carlos Costa, que se destinaba a la madres, dando consejos sobre el amamantamiento y los cuidados del bebe, en una divulgación de la higiene dentro de los moldes científicos de la época. ${ }^{3}$ La revista Sciencia para o Povo (1881), editada por Felix Ferreira, y volcada para los aprendices de la enseñanza técnica del Liceo de Artes y Oficios, también se preocupaba en traer al público "la nacionalización de los compendios", así como ofrecer a los mismos lectores traducciones de obras de popularización de las ciencias, como el libro sobre higiene y nutrición de Aristide Roger, Votre Histoire et a mienne, de $1874 .^{4}$

Acciones variadas, para posibles públicos diferentes - no obstante las dificultades de conocer el perfil más exacto de los lectores - indican tanto la existencia de tipos de divulgación de las ciencias, así como también la presencia de vulgarizadores que se distinguen por su relación con la propia actividad científica. Dentro de tales acciones, estamos considerando las propias traducciones de popularizadores consagrados en otros contextos nacionales. Tales traducciones indican tanto la existencia de un tipo de acción mediadora entre ciencia y público de los traductores, cuanto la circulación de obras de cuño popularizador en el período.

En este artículo, llamamos la atención para las traducciones para portugués de las obras del francés Louis Figuier, vulgarizador de las ciencias de gran suceso en Francia. Sus obras reflejan un modelo de divulgación científica de gran alcance en el contexto francés, resultando en diversas ediciones y traducciones para lenguas extranjeras. Conviene así reflexionar sobre los significados de este tipo de producción so- 
bre las ciencias destinado a un público más amplio, cuja repercusión en Brasil puede ser acompañada a través de las traducciones de varios de sus textos, incluyendo libros, como Os sábios ilustres (1869) [Vie des savants illustres], As grandes invenções antigas $e$ modernas (1873b) [Les grands inventions anciennes et modernes], O homem primitivo (1883) [L'homme primitif], traducidos por editoras luso-brasileras por Augusto Emilio Zaluar, António Plácido de la Costa y José Manuel Felgueiras, respectivamente.

Una mirada más detenida sobre algunas estrategias del vulgarizador en relación a los contenidos de ciencias transmitidos por él, así como las propias concepciones sobre las relaciones entre público y ciencia, permiten establecer los nexos entre la divulgación de las ciencias y una narrativa contenida en la historia de las ciencias que se hace canónica hasta la primera mitad del siglo XX, repercutiendo a su vez, ciertos usos de la historia ochocentista, en particular de la historia nacional. En este sentido, es posible entender la figura de los vulgarizadores - que aquí se consideran tanto los autores como los traductores - como diseminadores de una forma de pedagogía conducida en contextos nacionales y que resalta principalmente la indagación sobre el público o sobre el "pueblo".

\section{LA VULGARIZACIÓN DE LAS CIENCIAS Y LOUIS FIGUIER}

Louis Figuier puede ser considerado un autor representativo de la época de crecimiento de la cultura científica de mediados del siglo XIX en Francia, cuando se observa una penetración de diferentes producciones científicas en la vida de las personas comunes, conjuntamente con políticas de estado que promovían la producción científica, o cuando, según la expresión de Fox, la ciencia alcanzó una faceta pública en aquel país (Fox, 2012). La segunda revolución industrial trajo un nuevo orden en el cual la vida material pasó a ser dictada por nuevas capacidades técnicas y por la idea del progreso. Diversas acciones ampliaron el público de la ciencia, inicialmente en Inglaterra y Francia, con el fenómeno de "popularización de la ciencia", tales como lecturas públicas, espectáculos, exposiciones y diversas publicaciones impresas (Lightman, 2007; Secord, 2014; Fox, 2012). En el caso francés, tanto la ampliación de la instrucción pública, como el crecimiento del mercado editorial para libros didácticos y paradidácticos (Mollier, 2008) posibilitaron el proceso donde surge la figura del vulgarizador profesional.

La vulgarización científica es generalmente reconocida como marca de ese tiempo, cuyas fases de suceso y ocaso pueden ser acompañadas a través de determinadas "configuraciones de las relaciones entre sociedad y ciencia", según los términos de Bensaude-Vincent (Bensaude-Vincent, 2009, p. 360). En la perspectiva de algunos autores, (Raichvarg y Jacques, 1991; Bensaude-Vincent, 2010; Béguet, 1990; entre otros) la vulgarización científica es una práctica específica de la difusión del conocimiento científico que tiene su era de "esplendor" a partir de la década de 1850, en función de las actividades de editores y autores, incluyendo entre ellos a Louis Figuier. Al lado de otras figuras, como Camille Flamarion, el abad Moigno, Gaston Tisandier, Victor Meunier, entre otros, Figuier fue uno de los principales protagonistas del movimiento de vulgarización de las ciencias, que formó parte de una generación que se especializó en la promoción de contenidos sobre ciencia para el gran público.

Es necesario, sin embargo, reflexionar sobre el significado del uso del término "vulgarizador". Desde por lo menos la segunda mitad del siglo XIX, las diferentes iniciativas de agentes - escritores, periodistas, profesores, editores, diseñadores y traductores, entre otros - que pretendían "tornar común" y hacer conocer la ciencia a un público amplio, fueron conocidas las expresiones "vulgariser" $\mathrm{y}$ "vulgarisation de la Science" en el ámbito francés, y en Inglaterra por la expresión "popularization of science". Si ambos términos indicaban las acciones de diseminación y divulgación de la ciencia para el gran público ${ }^{6}$, la particularidad del término francés asume características que inducen a una reflexión sobre sus implicaciones. Como resaltó Bensaude-Vincent, el término vulgarización no es neutro, y supone una transposición o una traducción de la ciencia a un público que es predefinido y marcado esencialmente por una "falta" (Bensaude-Vincent, 2009).

El termino "vulgarización" usado en el espacio francés pasó a ser utilizado en Brasil de forma más intensa en la década de 1870 (Vergara, 2003, p.9). Un ejemplo de este uso es la revista publicada por Augusto Emilio Zaluar El Vulgarizador entre 1877 y 1880. ${ }^{7}$ Para Vergara, si en el siglo XIX en Brasil el término "vulgarización científica" designaba la acción de hablar de la ciencia para el lego, o plebeyo, en el siglo siguiente, "ese término fue cayendo en desuso en favor de otro, 'divulgación cientifica'." (Vergara, 2008, p. 325). En el siglo XX, así, se adoptó usualmente la expresión "divulgación científica" (Massarani, 1998, p.15), mientras que "vulgarización" ganó una connotación negativa, por su vinculación con la pérdida de un cierto aura de la ciencia. 
El vulgarizador tendría claro como proyecto educar y llevar el conocimiento científico a las camadas no esclarecidas en una vía de mano única, presuponiendo que sería necesaria la autoridad de los científicos profesionales para que esa traducción fuese validada. Es en ese punto que también se observan los límites de esa concepción de mediación entre ciencia y público.

Por un lado, porque, como observaron muchos autores, el término vulgarización, tomado como un neologismo por Littré ${ }^{8}$, nunca dejó de suponer su relación con el origen de la palabra latina "vulgus" y con "vulgata" de la Biblia" ${ }^{2}$, recordando la connotación negativa de las palabras "vulgaire" y "vulgarité", discutidas por madame de Staël, en el período pósrevolucionário $^{10}$ (Raichvarg y Jacques, 1991; Vergara, 2003). Bajo el riesgo de ser descalificada, la tarea de la vulgarización no podría ser autónoma frente al modelo de autoridad ejercido por los científicos. El propio proceso de institucionalización de las ciencias, cuya profesionalización de los científicos garantizaría la autonomía y auto reglamentación, fomentaba al mismo tiempo, vía especialización, el distanciamiento entre el conocimiento producido por los científicos y el público lego. La concientización de ese distanciamiento por parte de sectores letrados justificaba el surgimiento de la figura del vulgarizador que, en la busca de mantener los ideales iluministas de difusión del conocimiento, traería el eslabón necesario entre ciencia y público vis a una sociedad en continuo perfeccionamiento.

Por otro lado, porque la vulgarización en el ochocientos hasta inicio del siglo $\mathrm{XX}$, realizada por especialistas que viven de ese emprendimiento, necesitaba vivamente de un público-consumidor, que se expandía con el crecimiento del mercado editorial impulsado por las reformas de la instrucción pública. En ese aspecto, la vulgarización se presentaba principalmente como una práctica pedagógica particular, asociada al ejercicio de la seducción (Raichvarg y Jacques, 1991). Como señalan Raichvarg y Jacques, todos los llamados vulgarizadores agregaron cualificaciones como "amable", "delicada" y "divertida" a la ciencia a ser comunicada, demostrando una cierta semejanza en el modo de abordar la ciencia, o sensibilidad en común. La ciencia de los vulgarizadores no debería cansar o ser molesta, siendo necesarios recursos como una prosa fácil y hechos diversos que despertasen el interés y la curiosidad, narrativas que incluyesen el conocimiento del pasado de la ciencia y de los científicos, y bellas ilustraciones.

Si en Brasil fue posible observar la presencia de los textos traducidos por los vulgarizadores, debemos te- ner en cuenta que los límites reales de este tipo de acción se establecieron debido a la imposibilidad de la expansión de la universalización de la educación y por las barreras sociales, como se irá a discutir en el final del artículo. Pero primero, vamos a analizar al propio vulgarizador Louis Figuier.

\section{LOUIS FIGUIER Y LA “CIENCIA PARA TODOS”}

La trayectoria profesional de Louis Figuier parece ser emblemática para examinar el vulgarizador de las ciencias en el siglo XIX. Siguiendo el camino común de los científicos de su época, como su proprio tío Jean Figuier, profesor de química en la Escuela de Farmacia de Montpellier, Louis Figuier se formó en Medicina en la misma institución y buscó posteriormente una posición en la Facultad de Medicina en París, donde habría fracasado. En 1850, se tornó doctor en ciencias físicas en la Facultad de Toulouse y retornó a París en 1853, concursando para el cargo de profesor en la Facultad de Medicina. Al no obtener el cargo, se tornó en seguida profesor en la Escuela Superior de Farmacia. Colaborando con periódicos científicos del momento, Figuier se confronta en polémicas con Claude Bernard sobre la función glucogénica del hígado, lo que lo tendría llevado a abandonar la carrera científica. Aconsejado por François Arago, astrónomo y eminente figura del republicanismo francés, pasó a dedicarse a la vulgarización (Raichvarg y Jacques, 1991, p. 59; Cardot, 1993, p. 8).

En 1851, comienza a publicar la Exposition et histoire des principales decouvertes scientifiques y crea en 1856 el L'Année scientifique et industrielle, almanaque o "repertorio anual de ciencias prácticas", que noticiaba los nuevos inventos en el campo de las ciencias aplicadas. El almanaque dirigido por Figuier duró hasta poco antes del inicio de la Primera Guerra y se tornó uno de los modelos más exitosos de la vulgarización científica del período, al dar centralidad a las noticias relativas a los nuevos artefactos tecnológicos del mundo moderno. Como explica en su introducción escrita en el aniversario de veinte años de la publicación, el Année scientifique fue un proyecto presentado al editor Louis Hachette, que ya desde su inicio pretendía alcanzar a un público no especialista.

Su relato sobre el proyecto es interesante para reflexionar sobre la concepción editorial y la idea de público que involucraba. Cuenta que, en una mañana, cerca de veinte años atrás, encontrara al célebre editor Louis Hachette, y que le propusiera dar inicio a una publicación al comienzo de cada año, en formato Charpentier, como entonces se denominaban las 
colecciones. Ésta sería un espacio consagrado a dar un panorama de los descubrimientos y de los trabajos alcanzados durante el año precedente, no de las ciencias puras, cuyo campo sería infinito, sino de las ciencias prácticas, cuya esfera era considerada más limitada y más accesible. La publicación tenía como modelo el periódico alemán Jahrsbericht, en el cual se resumían los progresos anuales de las ciencias, en particular de la fisiología y la química. En Francia, ya existía este género de publicaciones, tales como los Rapports annuels des progrès des sciences chimiques, del sueco Berzélius, el Repertoire annuel de chimie, del químico francés Millon, y el Annuaire de chimie, de Charles Gerhardt, que rivalizaba con las ideas de la publicación de Berzélius. Pero, como resaltaba Figuier, tanto el Rapports annuels sur les progrès de la chimie, como el Repertoire... de Millon se reportaban solamente a una ciencia particular, permaneciendo poco conocido por el resto de los sabios, y totalmente ignorados por la gran masa de público. El propósito del Année Scientifique se justificaba de esta forma:

\footnotetext{
"Me parecía que aplicando la idea de estos resúmenes anuales al conjunto de las ciencias útiles rendiría un servicio inmenso. Deberíamos dirigirnos, por este medio, a la masa entera del público que, en general desprovisto de conocimientos científicos, tiene necesidad de mantenerse a la par de los nuevos descubrimientos." ${ }^{11}$
}

En su concepción, una publicación que sirviese a la sociedad en general ("gens du monde", de acuerdo con Figuier), debería mantenerla informada de las nuevas conquistas de las ciencias aplicadas, otorgando de antemano una selección que, los periódicos científicos, por su lenguaje técnico y excesiva especialización, no podrían proveerle. Se puede también acrecentar que el Année Scientifique se benefició de los grandes eventos de celebración de las conquistas materiales de la civilización europea que fueron las ferias internacionales. En un ambiente propicio para la exaltación de los productos de la industria, Figuier participó en la prensa publicando folletines durante la Exposición Universal en París, en 1855. Este material se convertiría en la primera muestra que le ayudaría a organizar los contenidos de los primeros números del anuario. Como el propio autor apostara con su editor, el almanaque se tornaría rápidamente un éxito. En tres meses, la tirada inicial saltaba de 3.000 para 6.000 ejemplares. En tres años, eran 8.000 ejemplares, y en 1877 , fueron impresos 15.000 (Cardot, 1993, p.26).

La proficua actuación de este autor parece estar en su capacidad de establecer desde el inicio del proyecto editorial a su público y dominar su papel bien definido como vulgarizador. Tales textos, como notó Béguet, deberían tener como objetivo lo práctico, lo aplicado, lo histórico, lo curioso y lo maravilloso al mismo tiempo (Béguet, 1990, p. 20). Fabienne Cardot, en un catálogo para la exposición sobre Figuier ocurrida en Nîmes, clasificó su producción escrita en algunos tipos. Entre ellas se encuentran: como las obras generales de vulgarización, donde constan libros como Les merveilles de la Science (1867-1870) y Le savant du foyer (1864), y el almanaque L'Année scientifique; obras especializadas de vulgarización, como Histoire des plantes (1880) y el L'homme primitif (1870); publicaciones científicas; teses en las áreas de química y farmacia; obras para-científicas, en las cuales trató de ideas del espiritismo; además de piezas teatrales. Entre estas últimas, se encuentran textos que tematizan viajes científicas como Les six parties du monde; así como la vida y obra de inventores y científicos, como Kepler, Gutenberg, y Le Mariage de Franklin. Esta diversificación de sus iniciativas lo convierte en emblema del ideario de la ciencia para todos. Otro destaque que merece atención son los libros para escuelas primarias. Figuier, así como otros publicistas de su época, se comprometió con la venta de libros de bajo costo, como Les merveilles de la science, a 10 centavos.

\section{EDUCACIÓN VOLCADA PARA EL PUEBLO Y LA JUVENTUD A TRAVÉS DE LAS CIENCIAS Y LA HISTORIA}

Como resaltado, las obras de Louis Figuier surgieron en la esfera del proyecto intelectual de la "instrucción divertida", pretendiendo hablar a un público constituido tanto por jovenes como por trabajadores. Sin embargo, el énfasis de sus obras se encuentra menos en la fantasía y la diversión y más en el didacticismo posibilitado por la transmisión de contenidos de ciencia precisos.

Figuier generalmente defendía su ideario sobre la vulgarización en las introducciones y prefacios, como en el prefacio de La Terre avant le déluge (1872d). Para él, el primer libro que debería colocarse en las manos de un niño tendría que ser un libro sobre la Historia Natural, en vez de libros de cuentos y fábulas, como de La Fontaine. Para Figuier, historias como la de El gato con botas, Los doce trabajos de Hércules, o la Piel de Asno solamente alimentarían en el espíritu infantil mentiras peligrosas inclinándose al misticismo y a las concepciones quiméricas. Para Figuier, se entrañaba en el niño el sentido de la locura, de la mentira, del absurdo, de lo imposible con dioses, semidioses y un cuarto de dios, 
diabliños, hadas, silfos, duendes, espíritus buenos y malos, encantadores, magos y diablitos.

"En una etapa en que la inteligencia es como una cera blanda, ella toma y conserva las impresiones más falsas, mientras que, virgen aun de todo conocimiento, es ávida por adquirirlo, nosotros la distorsionamos, la aniquilamos desenfrenadamente, y nos espantamos que esa inteligencia, que esta cera blanda y dócil, conserve más tarde la marca indeleble de los absurdos que en ella grabamos". ${ }^{12}$

En una edad tan tierna, no sería posible evitar que su alma no se tornase presa fácil de la ignorancia, de las supersticiones, y de las vacilaciones del espíritu público - como en su opinión, era el socialismo. Los primeros libros de la infancia no deberían así sobreexcitar la inclinación a lo maravilloso ya presente en el niño. Al contrario, debido a la propensión natural de los hombres a la imaginación, no sería demás traer en una edad tierna la formación de la contemplación sabia y razonable del mundo natural y técnico a través de la mirada de la ciencia, llevando tanto al joven como a la población trabajadora a la "diligencia honesta de un espíritu correcto, firme y esclarecido" (Figuier, 1872d, p.3). Los primeros libros de la infancia por lo tanto, no deberían fortalecer tal inclinación, y sí, consolidar la razón.

Figuier por otro lado, reconoce que no sería posible mutilar del alma humana su aspecto maravilloso, donde toda poesía y literatura tendrían fundamento. Retirada esa parcela del alma, continuaba en el prefacio, una generación criada únicamente bajo los auspicios de la razón estaría desprovista de todo ideal, toda imaginación y sentimiento. Tal generación sería una colección de máquinas de calcular. Sin embargo, la capacidad imaginativa no desaparecería del espíritu humano, ya que sería parte constitutiva de la inteligencia, y se alimentaría de nuevos conocimientos, que deberían ser provistos por el conocimiento científico. Era así preciso llenar la inteligencia con principios exactos y precisos, nutrirla de 'verdades incontestables'.

Figuier encarna así la idea de la "educación para todos", en la cual la formación a través de los contenidos adquiridos a partir de los conocimientos científicos, desde la invención de la imprenta, por Gutenberg hasta el microscopio, serían parte de una pedagogía mayor, que incluía el propio ethos de la ciencia en la formación de toda la sociedad y su preparación para un mundo futuro, una utopía científica. De estas enseñanzas, creía que no solo se beneficiarían los niños, como también los jóvenes y trabajadores de las fábricas y campesinos. En la ad- vertencia con la cual introduce As grandes invenções antiguas e modernas, ${ }^{13}$ defiende la ventaja que tendría substituir la enseñanza "moral" de los cuentos y mitos tradicionales por la exposición de las invenciones científicas (antiguas y modernas):

"Como hasta hoy, las obras destinadas a los jóvenes han tenido por asunto la moral, la historia o cuentos instructivos solamente, nos pareció que la exposición elementar de las grandes invenciones científicas e industriales antiguas y modernas, daría el mismo resultado con más ventajas. (...) Los mancebos, acabados sus estudios, encontrarán, en cualquiera de las carreras que sigan, aquello que constituye la materia del presente libro. El obrero de las fábricas, el cultivador en el campo, el empleado, el comerciante, tendrán que recurrir constantemente a la máquina a vapor, a la electricidad, al gas de iluminación, etc., porque hoy en día y en todas partes, la ciencia ha penetrado en la vida común. Es, por lo tanto, indispensable familiarizarnos desde la infancia con las ciencias que tantos servicios nos prestan en el curso de la vida." (Figuier, 1884, pp.5-6).

Recordaba también que en la obra Les merveilles de la Science (1867) el conocimiento científico no era más, como medio siglo atrás, un tipo de "lujo intelectual" o un simple complemento de una educación distinta.

Las maravillas técnicas y científicas modernas presentadas por Figuier encajaban en la clave de la instrucción divertida, pero en un camino distinto al fantástico y de la ficción encontrados en las obras de Julio Verne. La preocupación de Figuier era sobre todo la de educar por medio de la ciencia, una vez que entraba en acción el mediador capaz de 'simplificar' el lenguaje por demás árido de la ciencia, a un público joven o de adultos no-especialistas. El aspecto "curioso" promovido por los nuevos descubrimientos debería ser restricto como instrumento para la verdadera instrucción o, como escribía en el prefacio de La terre avant le déluge, la curiosidad se daba como "flores" tiradas en el camino del aprendizaje de las ciencias duras (Figuier, 1872d, p. 5).

Las ilustraciones que acompañaban sus libros y revistas, más que un recurso de mero auxilio, se tornaban en un elemento constitutivo del propio lenguaje de la vulgarización científica, al criar una estética propia para las obras. En divesos libros de Figuier, es posible ver el postulado de las "ciencias positivas" inspirado en Comte. Al buscar estimular los sentidos de los lectores con imágenes, sus obras exponían las conquistas científicas, tornándolas accesibles, objetivas y claras, realizando al mismo tiempo una difusión visual del conocimiento. Se trata de una importante 
llave de la apropiación por parte de los lectores de los contenidos narrados en el texto.

Como señala Béguet, entre pedagogía y diversión, se trataba también de una "educación por los ojos", ya presente en parte en la cultura iluminista de los espectáculos y experimentos científicos, y que se acentúa durante el siglo XIX bajo formas que variaban de revistas y libros a teatro y proyecciones luminosas (Béguet, 1990, p. 39). Figuier fue uno de los pioneros en las ediciones que acompañaban bellas ilustraciones, siendo ellas un llamativo seductor del emprendimiento popularizador. Para la realización de las ilustraciones, el diseñador - él mismo un especialista - precisaba tener conocimientos específicos de los objetos científicos retratados, agregando las más recientes informaciones en cada área científica. En diversas introducciones el autor explicaba cómo las ilustraciones eran hechas a partir de la observación de especies y colecciones encontradas en los jardines botánicos o en los museos de historia natural. El libro La Terre avant le déluge, por ejemplo, contiene 30 vistas ideales de paisajes del mundo antiguo con 316 figuras y 8 cartas geológicas coloridas. En el prefacio, explica que el diseñador Édouard Riou, conocido por también colaborar con las obras de Julio Verne, imitaba una publicación que había sido hecha en torno de 1850 por el director del Jardín Botánico de Viena, el doctor Unger, ejecutando diseños de paisajes representando imágenes de la tierra durante cada período geológico, reuniendo plantas y animales que serían propios de cada uno de los períodos retratados. De la misma forma, en el libro L'homme primitif de 1870 , sobre el hombre prehistórico, eran retratadas 40 escenas de la vida del hombre primitivo diseñadas por Emille Bayard. En esas escenas, es posible ver las representaciones de cómo fueron los "usos y costumbres" en épocas geológicas distintas, en una etapa de la vida humana "antes de la historia", como en la expresión del autor. En las imágenes están representadas escenas imaginarias de mujeres y hombres en un banquete fúnebre o cazando en la "época de los mamuts", pero también se encuentran retratados objetos de los más variados hallazgos arqueológicos, como arpones, lanzas de sílex y esqueletos encontrados en grutas.

Cabe decir aquí que en las tres obras sobre los orígenes del hombre y la prehistoria, La terre avant le déluge (1863), L'homme primitif (1870), Les races humaines (1872a), Figuier defiende el creacionismo y el monogenismo. Como señaló Robert Fox, en el campo de los orígenes del hombre, Figuier asumió una posi- ción más tradicional, en vez de adherir al Darwinisimo (Fox, 2012, p. 206). Es interesante recodar que tanto Camille Flammarion como Figuier, ambos vulgarisateurs franceses, tropezaron con temas relacionados con las creencias religiosas y la ciencia. Flammarion se tornó conocido por su aproximación con Alain Kardec y el espiritismo. En el caso de Figuier, las especulaciones sobre la vida y el alma después de la muerte están presentes en el libro Le lendemain de la mort (1871), publicado un año después de la pérdida de su único hijo. Cabe señalar que este libro fue traducido para el portugués con el título Depois da morte, ou a vida futura segundo a ciência (1877) por el Dr. Ferreira de Araújo, periodista y director del diario Gazeta de Notícias y fue vendido en los catálogos Garnier librería, por el precio de $4 \$ 000$ (quatro mil réis).

O Homem primitivo (1883), libro traducido por un profesor de la ciudad de Porto, Manoel José Felgueiras, también circuló en Brasil. En él, defendió la idea de que los hechos científicos no habían contestado hasta entonces de forma contundente la inexistencia de la creación divina. Su creencia, sin embargo, no se oponía a la práctica de la compilación y actualización de nuevas informaciones y resultados que obtenía de investigaciones en varias áreas de la ciencia de su época, fomentando así constantemente su papel de mediador entre la ciencia académicamente producida y los legos. En efecto, en una sociedad mayoritariamente católica como la brasilera, es probable que obras que defendiesen los orígenes bíblicos tuviesen aceptación entre los lectores.

Volcado para la sociedad de masas que era engendrada en la Europa del siglo XIX, el discurso de los vulgarizadores se elaboraba como una práctica pedagógica, en la cual la historia de la ciencia - una historia universal y nacional al mismo tiempo - con sus héroes y sus conquistas en sucesión progresiva y acumulativa en el tiempo histórico, ocuparía un papel central. No obstante la continuidad de buena parte de ese ideario en la producción posterior de la divulgación científica a lo largo del siglo XX, se puede decir que en el campo editorial, el suceso de la fórmula de los vulgarizadores no mantuvo el mismo vigor después del pasaje de siglo, siendo observable una merma en las tiradas en los años anteriores a la Primera Guerra. Los textos de los vulgarizadores no generaban más el entusiasmo que en las décadas anteriores, y cada vez más las obras de contenidos científicos se alejaban del interés de un público de elite, mientras que la "difusión del conocimiento" para todos se convertía en un papel legado a las escuelas oficiales (Béguet, 1990, p.19). 
TRADUCCIONES PARA EL PORTUGUÉS Y LA CIRCULACIÓN DE LAS OBRAS FRANCESAS DE VULGARIZACIÓN CIENTÍFICA

Es cierto que tal movimiento intelectual de la "educación para todos" que acompañó el período de auge y de decadencia de los vulgarizadores se mostró limitado en Brasil durante el siglo XIX, debido, entre otras causas, a la esclavitud y a las dificultades de expansión de la escolaridad en el país. Mismo así, ese ideal ganó cierto impulso por agentes que vislumbraban una mayor participación del país en el nuevo mundo producido por las mudanzas tecnológicas, en particular, intelectuales comprometidos con proyectos de modernización, dirigidos por la "generación de 1870" de Brasil, que desafió en diferentes frentes al orden monárquico y sus bases de apoyo, tales como el romanticismo en el campo de la estética, la filosofía ecléctica, el catolicismo y la esclavitud (Alonso, 2002).

A través de movimientos como las conferencias populares en boga entre las décadas de 1860 y 1870, se formulaba una de las facetas del ideal civilizatorio del "concierto de las naciones" que estuvo presente en Brasil. Desde mediados del siglo XIX, aumentaba el número de revistas que proponían diseminar temáticas científicas para un público no especialista, con el objeto de dar foco a una ciencia producida en el país. Tal era el objetivo de publicaciones como la Revista Popular, surgida entre 1859 y 1862, y editada por la casa Garnier o la Revista Brasileira, entre otras (Venancio, 2013; Vergara, 2003). Las conferencias públicas, mismo que no propiamente populares, parecen haber comenzado, según Freitas, con la expedición liderada por Louis Agasiz, en 1865. A partir de una invitación hecha por el Colegio Pedro Il y apoyada por el emperador, las conferencias, que eran proferidas en francés, traían un público de elite que pasó también a incorporar la presencia de mujeres (Freitas, 2002, p. 57). Talvez, las más conocidas manifestaciones de ese ideal, mismo que de carácter limitado, hayan sido las Conferencias de la Gloria, ocurridas entre 1873 y 1889, y reanudadas en 1891 hasta la primera década del siglo XX. Desde las décadas de 1870 y 1880, como enfatizó Moema Vergara, el término "vulgarización científica" ya era utilizado en Brasil, como en la publicación de Augusto Emilio Zaluar intitulada O vulgarizador (Vergara, 2008, p. 140). Este mismo autor se tornó uno de los traductores para el portugués de los escritos de Louis Figuier, lo que nos lleva a reflexionar sobre el papel de los mediadores entre ciencia y sociedad a través de la circulación de textos de popularización en contextos nacionales distintos.
La circulación de las obras de Figuier puede ser constatada a través de las traducciones en diferentes lenguas. Al depararnos con la difusión y el número de versiones en otras lenguas de sus libros, talvez sea posible dimensionar aspectos de una internacionalización de la cultura de la ciencia del período. Las traducciones pueden igualmente auxiliarnos a reflexionar, a partir de las localidades, cómo el ideario de la popularización de la ciencia - que tuvo como objetivo el establecimiento de una forma hegemónica de ver a las ciencias, para utilizar el argumento propuesto por Kostas Gavroglu (2012) - se incorporó en los proyectos nacionales de modernización. A partir de las traducciones talvez sea posible observar cómo circulaban conocimientos sobre las ciencias para una cierta cultura científica, entendiendo las diferentes motivaciones, usos y significados del ideal de la "ciencia para todos" que emerge en la segunda mitad del siglo XIX.

No sería demasiado recordar que el vasto alcance de las obras de los vulgarizadores está vinculado al desarrollo de los emprendimientos editoriales en diferentes países. ${ }^{14}$ Figuier señaló la existencia de plagios de sus libros en los prefacios de L'Année Scientifique, por ejemplo, la traducción de Les grandes inventions anciennes et modernes, por Besso, y partes del propio almanaque. Por los tratados internacionales, hasta el momento en que escribía, el autor no tendría derecho a reivindicar la autoría sobre las traducciones después de pasados dos años de la edición del original. De todas formas, obras posteriores de Figuier fueron traducidas al italiano, con las debidas credenciales, tales como Vita y costumi degli animali. I mammiferi, y Vita y costumi degli animali. Rettili, pesci y animali articolati, de 1881.

Las publicaciones de Figuier serán replicadas en diferentes lenguas y en diferentes países, en las traducciones de sus obras al inglés, sueco, español, italiano, portugués, confluyendo con el movimiento de las conferencias públicas científicas y los proyectos de creación de bibliotecas populares. En el caso argentino y chileno, por ejemplo, Domingo Sarmiento adaptó y tradujo para su proyecto de Bibliotecas Populares, la "Exposición e historia de los descubrimientos modernos", por Julio Belín y Cia, en 1854. En 1867, la librería e importadora de Madrid, Gaspar y Roig editó Los Grandes inventos: antiguos y modernos: en las ciencias, la industria y las artes, traducida por Manuel M. Flamant. En portugués, Figuier ya aparece en algunos textos traducidos en periódicos y revistas en la década de 1850 . En 1855, la revista O Auxiliador da Indústria Nacional, publicaba un artí- 
culo extraído del diario La Presse, intitulado "Las máquinas de vapor en la Exposición Universal de París" (Figuier, 1855), sin assinatura del traductor. Décadas después, sus obras traducidas eran vendidas principalmente por H. Garnier librería. La primera traducción de libro conocida es la obra Os sábios ilustres. Christovão Colombo, en 1869, por Augusto Emilio Zaluar, editor del periódico $O$ Vulgarizador. También fue traducida en el período As grandes invenções antigas e modernas nas sciencias - Obra para uso de la mocidade que sería editada en Porto, por la Librería Internacional de Ernesto Chardron, en 1873, por Antonio Plácido de la Costa, que se tornaría un conocido histólogo y profesor en la Escuela Médico-Quirúrgica de Porto. La editora Garnier publicó Depois da morte, ou a vida futura segundo a sciencia, en 1877, traducido por Ferreira de Araújo. En secuencia, todavía encontramos traducidas al portugués en la década siguiente As raças humanas (1881) por Abílio Lobo, y el ya mencionado $O$ homem primitivo (1883), ambos editados por la Empreza Litteraria Luzo-Brazileira en Lisboa, que vendía en Portugal y en Brasil.

Podemos tomar al traductor Augusto Emilio Zaluar como un ejemplo de mediador de la cultura científica que se fortalecía entre los intelectuales brasileros en los años finales del Imperio, haciendo circular en el país diversas corrientes de pensamiento ligadas al cientificismo, materialismo y evolucionismo, en suma, al "bando de ideas nuevas" a la que se refería uno de los principales exponentes de la generación de 1870, el crítico literario, profesor del Colégio Pedro II, y polemista Silvio Romero. Nacido en Lisboa, Zaluar se muda a Rio de Janeiro, viniendo a fallecer en 1884. Él es el autor de la ficción Doutor Benignus (1876), considerado por muchos, el primer libro de ficción científica escrito en Brasil, o según la definición del autor, una "novela científica". En él, se introducen ideas darwinistas, discutiendo así para el público lector de novelas, asuntos como la selección natural y la evolución (Waizbort, 2012). Zaluar fue evaluador de la Instrucción Pública y profesor de la Escuela Pública Normal (Duarte, 2010), y su fuerte ligación con la causa de la instrucción pública torna posible comprender sus iniciativas como editor de la revista $O$ Vulgarizador (1877). La revista editada por Zaluar posee sin duda alguna, inspiración en las publicaciones de los vulgarizadores franceses, en particular, Figuier. Algunos textos d'O Vulgarizador posibilitan resaltar las semejanzas entre el traductor y el autor, como por ejemplo, el artículo de la revista que presenta el microscopio de Nachet, cuyos primeros modelos habían sido criados en torno de la década de 1850. Así como en el texto de Figuier, la presentación del "invento" para el gran público incluía expresiones como el maravilloso "mundo de los infinitamente pequeños", bien como mencionaba los modelos del microscopio - el simples y el compuesto - y citaba a Zacarias Jansen como autor del primer modelo, que habría sido criado en 1590. En esa narrativa, queda claro como la historia se torna parte del método de popularización.

La generación que surgía a fines de la Monarquía e inicio de la República, a través de autores y libros que exaltaban un camino ascendente para la nación, imprimían una pedagogía particular, en la cual la ciencia tendría un papel fundamental. Esta exaltación de la ciencia y del cientificismo que constituía parte de su cultura política, entretanto, no sería posible sin el instrumento que le permitiese generalizarla: el discurso histórico que reforzaba como parte constitutiva de su narrativa la ejemplaridad de los grandes hombres, en el modelo de Plutarco (Enders, 2000). Así, si la escrita histórica ochocentista asumía los contornos de la veracidad potenciada por las ciencias naturales, popularización de las ciencias no podía prescindir del propio discurso historiográfico ochocentista, entonces en curso en Brasil. Como resaltó Oliveira (2011), "la biografía era exaltada tanto por su capacidad de tornar vivos los personajes y las épocas históricas como por la fuerza persuasiva de sus lecciones. Se trataba por lo tanto, de un género de escritura que atendía a los imperativos más inmediatos del programa de la historia magistra vitae: fijar los nombres y ejemplos del pasado, ofreciéndolos a la imitación de los lectores en el presente" (Oliveira, 2011, p. 59). Figuier, a través de sus obras, al mismo tiempo que posibilitaba una mayor diseminación de la cultura científica por un "método" histórico dominante, también reforzaba el propio discurso engendrado por la naciente disciplina de la Historia de las ciencias.

Esa estrategia de cautivar al público a través de la historia de los personajes ilustres para la ciencia, puede ser encontrada en Vies des savants illustres: depuis I'antiquité jusqu'au dix-neuvième siècle, publicado por Figuier como colección, entre 1866 y 1870 . Dividida en 5 tomos, contemplaba los títulos Savants de l'antiquité (1866), Savants du moyen âge (1867), Savants de la renaisance (1868), Savants du XVIle siècle (1869) y Savants du XVIIle siècle (1870). Del segundo tomo es de donde Zaluar extrajo la traducción al portugués de Os sábios ilustres- Cristóvão Colombo. Siguiendo una escritura clara, y de manera bastante fiel al original en francés, el libro presenta la vida del navegador geno- 
vés contada por Figuier, basada en diversas biografías y textos entonces disponibles, como el de Bartolomé de Las Casas y de Fernando Colombo. La traducción es bastante fiel al texto original y tiene una escritura bastante fluida, en una historia que narra la aventura de Colón hasta las Américas y su trayectoria de vida.

\section{CONCLUSIÓN}

En otras palabras, "la ciencia enseñada por la historia", tal como encontrada en los textos de Figuier, formulaba el conjunto de temáticas y síntesis presentes en la historia de las ciencias tradicional en el siglo XIX e inicio del XX. El mote de una historia que cuenta y enseña la ciencia y sus valores estaba presente igualmente, como escribe Heizer, en el espíritu de otras acciones, como las exposiciones universales. Las ciencias, mostradas por la historia, se tornarían un aprendizaje del camino de la razón que iría de lo simple a lo complejo (Heizer, 2009, p. 4), sin ser tediosas o cansadoras. Sería ésta una especie de 'utopia científica', que todos los mediadores de la cultura científica del período buscarían defender.

En los textos de los vulgarizadores, los científicos también pasaban a ser consagrados como héroes nacionales, cuyo peso y medida se daba por las conquistas legadas al mundo y por su alcance universal. Un ejemplo de cómo ese culto a las personalidades científicas se construye, puede ser encontrado en el L'Année Scientifique, que pasa a incorporar en sus publicaciones las necrológicas de los científicos fallecidos cada año.

La valorización del conocimiento científico se vincula en sus obras a la propia narrativa histórica, en un modelo canónico de la historia de las ciencias. El desarrollo científico, visible por avances y conquistas, es indisociable de las historias y biografías de genios, cuyo ejemplo de vida debería auxiliar a formar nuevos "ciudadanos". Así, como en la historia política ochocentista, la ciencia de los divulgadores era contada por grandes hechos (las invenciones) y trataba acerca de grandes hombres. Los modelos ejemplares deberían comprometer al joven y a los no especialistas en los valores propios de la ciencia, enseñados a partir de las virtudes de aquellos dedicados al trabajo científico.

Se allí se verifica una pedagogía para la nación a ser también incorporada en Brasil, tal proyecto sufría limitaciones por la estrecha posibilidad de diseminarse, en medio del analfabetismo elevado y de la falta de acceso a la educación formal de la mayor parte de los brasileros, en los años finales del Imperio e inicio de la era republicana. Se sabe que, en ese período, la formación universitaria continuó restricta a pocos cursos como Derecho, Ingeniería y Medicina, mudando solamente este cuadro en la década de 1930; la matrícula en las escuelas primarias, hasta 1920 , no alcanzaba más que el $29 \%$ de la población en edad escolar en el país (Saliba, 2012, p. 250). La exclusión real de una buena parte de la población, por lo tanto, contradiría el ideal del conocimiento "al alcance de todos". La presencia de los traductores y publicistas que buscaban comunicar las ciencias a un público no especialista se configuraba en un proyecto destinado a las camadas medias, que tendrían mayor acceso, sea por el nivel de instrucción, sea por el poder adquisitivo, debido a los propios precios de buena parte de los libros. El libro Sábios illustres - Cristovão Colombo costaba $1 \$ 000$ reis en la lista del librero Garnier en $1873^{15}$, mientras que en la década de 1890, otras obras de Figuier, como $O$ homem primitivo y As grandes invenções, siendo ambas ilustradas, alcanzaban el precio de $16 \$ 000$ (dieciséis mil réis) y $25 \$ 000$ (veinticinco mil réis), respectivamente. Tales libros no deberían llegar a las manos de los trabajadores, cuando la media de la diaria de un trabajador podía girar en torno a $1 \$ 000$ (mil réis) a $3 \$ 000$ (tres mil réis) (Saliba, 2012, p. 248; Vergara, 2003, p.77). Mismo para profesores primarios, esos libros no eran baratos, ya que éstos recibían un salario mensual en torno de $150 \$ 000$ (ciento cincuenta mil réis).

Algunos valores fundamentales para el fomento a las ciencias, sin embargo, eran defendidos por mediadores de las ciencias entre las camadas medias, representadas por figuras como Augusto Emilio Zaluar, y hacen pensar que deseaban un país diferente. 


\section{NOTAS}

1 A pesar de que en español es más común el término popularización, optamos por el uso de "vulgarización" por remitirse a la matriz francesa. La palabra "vulgariser", que proviene de "vulgar" (vulgaire), infunde sin duda una visión negativa de la popularización, que indica la especificidad y las ambiguedades de la acción de divulgación por los denominados vulgarizadores. Más adelante, este tema será retomado.

2 Según Vergara, la Revista Brasileira, dedicada a las ciencias, la literatura y las artes, reunía un gran número de intelectuales con el propósito de transmitir una cultura de carácter nacional. En palabras de la autora, "a maioria das colaborações versava sobre assuntos científicos diversos, apresentados em relatórios, comunicações, memórias e ensaios assinados por nomes de projeção do meio científico brasileiro. Vergara, Moema (2003), A Revista Brasileira e a história da divulgação científica no Brasil oitocentista, tese de doutorado, Rio de Janeiro, PUC-Rio, p.68.

3 El periódico asumiría críticas al amamantamiento por amas de leche esclavas, resaltando al mismo tiempo una actitud antiesclavista y de condenación de los propios esclavos, considerados maléficos a la sociedad burguesa que pretendía consolidarse. Ver Carula, Karoline (2012), "Perigosas amas de leite: aleitamento materno, ciência e escravidão em A Mãi de Familia", História, ciência, saúde -Manguinhos [en linea], vol.19, suppl.1, pp.197-214 [Consultado el 16-05-2015].

4 Aristide Roger Rengade, Jules (1874). Votre histoire et la mienne, Paris, Librairie d'Éducation, Disponible online em: http://catalogue.bnf.fr/ark:/12148/cb311983307, [Consultado el 20/02/2015].

5 En la definición del Dictionnaire éncyclopedique universel contenant tous les mots de la langue Franciaise et résumant l'ensemble des connaisances humaines à la fin du XIXe siècle... Tome 8 (T-Z), de Camille Flammarion (1894-1898), es posible encontrar la siguiente definición para el verbo "vulgariser": "Rendre vulgaire, faire connaître, faire comprendre au plus grand nombre une science, une découverte, une docrtrine, etc. De toutes parts on s'efforce de vulgariser la science. il se chargea de vulgariser cette doctrine." Ambigüedad de hacer conocer para un número mayor una ciencia, un descubrimiento, una doctrina, y de tornar vulgar era así comprendida por los propios vulgarizadores.

6 Luisa Massarani destacó que el término "divulgación científica" tendría predominado en Brasil, como actividad que se desarrolló plenamente en el siglo XX. Massarani, Luisa (1998), A divulgação científica no Rio de Janeiro: algumas reflexões sobre a década de 20, Tesis de Maestria, Escola de Comunicação, Universidade Federal do Rio de Janeiro, Rio de Janeiro, p.15.

7 Sobre $O$ Vulgarizador, consultar el site: http://site.mast.br/ ovulgarisador/jornal.php
8 V. Littré, Emile. Dictionnaire de la langue française, Tome 4, L. Hachette, 1873-1874, p. 2555.

9 Ese aspecto ya era discutido por los propios vulgarizadores, como Camille Flammarion, y por aquellos que estudian la vulgarización y la comunicación de las ciencias. Moema Vergara por ejemplo, destaca que "vulgarizar", por estar ligado a la palabra vulgus en oposición a populus - o los ciudadanos en la Roma clásica - puede haber sido un elemento para la asociación de esa connotación negativa frente a la expansión del concepto de ciudadanía de fines del siglo XIX y durante el siglo XX.

10 Madame de Staël, en De la littérature, discute cómo el sentido de "vulgaire" como sinónimo de mal-gusto, es fruto de la contradicción generada por la diseminación de la alta cultura y de la eliminación de la distinción. V. Staël (Madame de) (1991), De la littérature, París, Flammarion.

11 “Il me sembla qu'en appliquant l'idée de ces résumés annuels à l'ensemble des sciences usuelles, on rendrait un servise immense. On devait s'adreser, par ce moyen, à la mase tout entière du public, qui, tout dépourvu qu'il soit de connaisances scientifiques, la pourtant besoin d'être tenu au courant des nouvelles découvertes." V. Figuier, Louis (1877), "Causerie avec les souscripteurs de L'Année scientifique". En: L'Année scientifique et industrielle. Tables des vingt premières volumes (1857-1877), Paris, L. Hachette et cie., p. 9. Disponible online en: http://gallica.bnf.fr/ark:/12148/ bpt6k2011067.zoom.langPT.r=L'Année\%20scientifique\%20 et\%20industrielle [Consultado el 24/05/2016]

12 Traducción libre del autor: "A une époque où l'intelligence est comme une cire molle, qui prend et conserve les plus faibles impresions, lorsque, vierge encore de toute connaisance, elle est avide d'en acquérir, on la fause, on la brise, comme à plaisir, et l'on s'étonne que cette intelligence, que cette cire molle et docile, conserve plus tard la marque indélébile des absurdités que l'on y la gravées." Figuier, Louis (1872d), La Terre avant le déluge, París, Librairie Hachette, p. 3.

13 Según Fabienne Cardot, Les grandes inventions anciennes et modernes, de 1861, tuvo 12 reimpresiones hasta 1863, y desde ese año hasta 1905, se conocieron 14 ediciones. V. Cardot, Fabienne (1993), Le savant du foyer. Louis Figuier et la vulgarisation scientifique au XIX siècle, Nîmes, Médiathèque du Carré d’art, p. 22.

14 De 1866 a 1873, al menos cuatro títulos de Figuier fueron traducidos por la editora D. Appleton \& Co. de Nueva York: The world before the deluge (1866); Mammalia. Their various orders and habits (1870); The human race (1872a); Reptiles and birds. A popular account of their various orders, with a description of the habits and economy of the most interesting (1873a). Otras obras también traducidas fueron editadas en Londres, Paris e Nueva, por Cassel, Petter, Galpin \& Co., como The insect world: a popular account of the 
orders of insects. A description of the habits and economy of some of the most interesting species (1872b); The vegetable world: a history of plants with their botanical descriptions and peculiar properties (1867); The Ocean World (1872c) y The Primitive Man (1876) por la editorial de Nueva York, G. P. Putnam's Sons, en el mismo período.

15 V. Catálogo dos livros de que é editor B. L. Garnier (1873), Rio de Janeiro, B. L. Garnier.

\section{BIBLIOGRAFÍA}

Alonso, Ângela (2002), Idéias em movimento. A geração 1870 na crise do Brasil-Império, Rio de Janeiro, Paz e Terra.

Aristide Roger Rengade, Jules (1874). Votre histoire et la mienne, Paris, Librairie d'Éducation, Disponible online em: http:// catalogue.bnf.fr/ark:/12148/cb311983307 [Consultado el 20/02/2015].

Béguet, Bruno (org) (1990), La science pour tous, 1850-1914, Paris, Bibliotheque du Conservatoire National des Arts et Métiers.

Bensaude-Vincent, Bernardette (2009), A historical perspective on Science and its "ohters", Isis, Vol. 100, No. 2, pp. 359-368.

Bensaude-Vincent, Bernardette (2010), Splendeur et décadence de la vulgarisation scientifique, Questions de communication [En línea], n. 17, pp.2-10. Disponible en URL: http:// questionsdecommunication.revues.org/368 (Consultado el 17/01/2015).

Cardot, Fabienne (1993), Le savant du foyer. Louis Figuier et la vulgarisation scientifique au XIX siècle, Nîmes, Médiathèque du Carré d'art.

Carula, Karoline (2009). A tribuna da ciência: Conferência Popular da Glória e o darwinismo na imprensa carioca, São Paulo, Annablume/Fapesp.

Carula, Karoline (2012), Perigosas amas de leite: aleitamento materno, ciência e escravidão em A Mãi de Familia, História, ciência, saúde-Manguinhos [en linea], vol.19, suppl.1, pp.197-214. Disponible en: http://www. scielo.br/scielo.php?script=sci_arttext \&pid=S010459702012000500011\&Ing=en\&nrm=iso [Consultado el 1605-2015]

Catálogo dos livros de que é editor B. L. Garnier (1873), Rio de Janeiro, B. L. Garnier.

Couty, Louis (1879), "Os estudos experimentais no Brasil", Revista Brazileira, tomo II, n.1, pp.215-239. Disponible online en: http://memoria.bn.br/DocReader/docreader. aspx?bib=139955 [Consultado el 24/05/2016].

Duarte, Denise (2010), “Augusto Emílio Zaluar: aspectos da trajetória e produção de um intelectual português no Bra- sil do século XIX", Temporalidades (en línea), v. 2, p. 123129 Disponible online en: https://seer.ufmg.br/index.php/ temporalidades/article/view/3069/2264 [Consultado el 24/05/2016].

Enders, Armelle (2000), "Plutarco brasileiro: a produção de vultos nacionais no Segundo Reinado", Revista Estudos Históricos, Vol. 14, No 25, p. 41-61.

Figuier, Louis (1855), "As machinas a vapor na Exposição Universal de Paris", O Auxiliador da Industria Nacional, vol. IV, Rio de Janeiro, Typographia de N. Lobo Vianna \& Filhos.

Figuier, Louis (1866), The world before the deluge, New York, D. Appleton \& Co.

Figuier, Louis (1867), The Vegetable World: a History of Plants with their Botanical Descriptions and Peculiar Properties, London, Chapman \& Hall.

Figuier, Louis (1869), Os sábios illustres. Christovão Colombo, [Tradução de A. E. Zaluar] Rio de Janeiro, Oliveira \& Cia. Editores.

Figuier, Louis (1870), Mammalia. Their Various Orders and Habits, New York, D. Appleton \& Co.

Figuier, Louis (1872a), The Human Race, New York, D. Appleton \& Co.

Figuier, Louis (1872b) The Insect World: a Popular Account of the Orders of Insects. A Description of the Habits and Economy of Some of the Most Interesting Species. London/Paris/ New York, Cassel, Petter, Galpin \& Co.

Figuier, Louis (1872c), The Ocean World, London/Paris/New York, Cassel, Petter, Galpin \& Co.

Figuier, Louis (1872d), La Terre avant le déluge. [Dessinées par Riou, 30 vues idéales de paysages de l'ancien monde. 316 autres figures et 8 cartes géologiques coloriées e J. Gauchard], Paris, Librairie Hachette.

Figuier, Louis (1873a), Reptiles and Birds. A Popular Account of their Various Orders, with a Description of the Habits and Economy of the Most Interesting, New York, D. Appleton \& Co. 
Figuier, Louis (1873b), As grandes invenções antigas e modernas nas sciencias. Obra para uso da mocidade, [Tradução de Antonio Placido da Costa], Porto, Livraria Internacional de Ernesto Chardron.

Figuier, Louis (1876), The Primitive Man, New York, G. P. Putnam's Sons.

Figuier, Louis (1877), “Causerie avec les souscripteurs de L'Année scientifique". En: L'Année scientifique et industrielle. Tables des vingt premières volumes (1857-1877). Paris: L. Hachette et cie., pp. 1-21. Disponible online en: http:// gallica.bnf.fr/ark:/12148/bpt6k2011067.zoom.langPT. r=L’Année\%20scientifique\%20et\%20industrielle [Consultado el 24/05/2016].

Figuier, Louis (1883), O homem primitivo, Lisboa, Empreza Litteraria Luso-Brazileira.

Flammarion, Camille (1894-1898), Dictionnaire encyclopédique universel contenant tous les mots de la langue française et résumant l'ensemble des connaissances humaines à la fin du XIXe siècle. Tome 8 (T-Z) / Camille Flammarion, Paris, E. Flammarion (Paris). Disponible online en: http:// catalogue.bnf.fr/ark:/12148/cb30439970h [Consultado el 31/03/2015].

Fox, Robert (2012), The savant and the State. Science and cultural politics in nineteenth-century France, Baltimore, Johns Hopkins University Press.

Freitas, Marcus Vinicius de (2002), Charles Frederick Hartt, um naturalista no Império de Pedro II, Belo Horizonte, editor da UFMG.

Fonseca, Maria Rachel Fróes da (2007), "As ciências biomédicas nas Conferências Populares da Glória (1873-1880)". En: Priego, Natalia; Lozano, Sonia (coord.), Paradigmas, culturas y saberes. La transmission del conocimiento científico a Latinoamérica, Vervuert, Iberoamericana/AHILA, pp. 105-133.

Gavroglu, Kostas (2012), "The ideology of popularization and the popularization of ideology: some issues for the History of Science", Revista Brasileira de História da Ciência, Rio de Janeiro, v.5, n.2, p.224-231.

Heizer, Alda (2009), "Ciência para todos: a Exposição de Paris de 1889 em revista", Fênix - Revista de História de Estudos Culturais (em línea), Jul/Ago/Set, vol. 6, n. 3, pp.1-22. Disponible online em: http://www.revistafenix.pro.br/PDF20/ ARTIGO_15_Alda_Heizer_FENIX_JUL_AGO_SET_2009.pdf [Consultado el 31/03/2015].

Lightman, Bernard (2007), Victorian popularizers of science: designing Nature for new audiences, Chicago, The University of Chicago Press.
Littré, Emile (1873-1874), Dictionnaire de la langue française, Tome 4, Paris: L. Hachette. Disponible online en: http://gallica.bnf.fr/ark:/12148/bpt6k54066991/f1166. image. $r=L i t t r e ́, \% 20 E ́ m i l e \% 20 d i c t i o n n a i r e$ [Consultado el 27/03/2015].

Massarani, Luisa (1998), A divulgação científica no Rio de Janeiro: algumas reflexões sobre a década de 20, Tesis de Maestria, Escola de Comunicação, Universidade Federal do Rio de Janeiro, Rio de Janeiro.

Massarani, Luisa; Moreira, Ildeu de Castro (2010), "A divulgação científica no Rio de Janeiro na década de 1920". En: Heizer, Alda; Videira, Antonio Augusto Passos. Ciência, civilização e ciência nos trópicos, Rio de Janeiro, MauadX/ Faperj, pp. 115-135.

Mollier, Jean-Yves (2008), A leitura e seu público no mundo contemporâneo, Belo Horizonte, Autêntica Editora.

Oliveira, Maria da Glória (2011), Escrever vidas, narrar a história. A biografia como problema historiográfico no Brasil oitocentista, Rio de Janeiro, Editora FGV/EDUR/Anpuh.

Raichvarg, Daniel e Jacques, Jean (1991), Savants et ignorants. Une histoire de la vulgarisation des sciences, Paris, Seuil.

Saliba, Elias Thomé (2012), "Cultura". En: Schwarcz, Lilia (coord.) História do Brasil Nação - A abertura para o mundo (1889-1930), v.3, Madrid/Rio de Janeiro, Fundación Mapfre/ Objetiva, pp. 239-294.

Secord, James A. (2014), Visions of Science. Books and Readers at the Dawn of the Victoriana Age, Oxford, Oxford University Press.

Staël (Madame de) (1991), De la littérature, Paris, Flammarion.

Vergara, Moema Rezende (2003), A Revista Brasileira e a História da Divulgação da Ciência no Brasil Oitocentista. Tese de doutorado, Puc-Rio.

Vergara, Moema Rezende (2008), "Ensaio sobre o termo "vulgarização científica" no Brasil do século XIX", Revista Brasileira de História da Ciência, Rio de Janeiro, v.1, n.2, pp.137-145.

Venancio, Giselle Martins (2013), "Ler ciência no Brasil do século XIX: a Revista Popular, 1859-1862", História, ciências, saúde-Manguinhos [online], vol.20, suppl.1, pp. 11531162. Disponible en: http://dx.doi.org/10.1590/S010459702013000400004 [Consultado el 08/02/2015].

Waizbort, Ricardo (2012), “O Doutor Benignus: a origem do homem na concepção de natureza de Augusto Emílio Zaluar", Revista Brasileira de História da Ciência, Rio de Janeiro, v. 5, n. 1, pp. 60-76. 